\title{
Selection Against Glycosylation in Ruminant Pancreatic Ribonucleases by Replacements in the Ancestral Carbohydrate Attachment Site
}

\author{
Matthias Gautschi · Jaap J. Beintema
}

Received: 28 December 2007/Accepted: 22 February 2008/Published online: 24 April 2008

(C) The Author(s) 2008

\begin{abstract}
A hypothesis, proposed 25 years ago, that there is selection against glycosylation in ruminant pancreatic ribonucleases by replacement of methionine to leucine in the ancestral carbohydrate attachment site Asn-Met-Thr at residues 3436, was experimentally confirmed. The replacement of leucine at position 35 by methionine in bovine ribonuclease resulted in a three-fold relative increase in glycosylation when expressed in Chinese hamster ovary cells.
\end{abstract}

Keywords Bovine - Glycoprotein - Molecular evolution · Ribonuclease ·

Ruminants

\section{Introduction}

One of the first successful applications of column chromatography in protein research was the separation of bovine pancreatic ribonucleases (RNase) A and B (Martin and Porter 1951; Hirs et al. 1953). First it was thought that there was a charge difference between the two components, until it was discovered that the minor one (B) is an Asn-linked glycoprotein (Plummer and Hirs 1963). However, the carbohydrate attachment site Asn-Leu-Thr (34-36) in this protein is glycosylated at less than $20 \%$ of the molecules (Hirs et al. 1953). This contrasts much with other mammalian pancreatic RNases (RNases 1) with one or more carbohydrate

\footnotetext{
M. Gautschi

Institute of Molecular Biology and Biophysics, Schafmattstrasse 20, ETH-Hönggerberg, HPKE 14, 8093 Zurich, Switzerland

\section{J. J. Beintema (ه)}

Department of Biochemistry, University of Groningen, Nijenborgh 4, 9747 AG Groningen,

The Netherlands

e-mail: j.beintema@home.nl
} 
attachment sites, which generally are fully glycosylated, like the RNases from pig and horse (Beintema et al. 1976).

Our studies on the molecular evolution of RNases 1 included 18 sequences from ruminant species (Pecora). Figure 1 shows the sequences of residues 34-36 in the ruminant part of an evolutionary tree of RNases 1 (Beintema and Lenstra 1982). Ten of the 18 sequences have Asn-Leu-Thr at these positions with minor glycosylation at eight sequences (bold italic letters). Much carbohydrate attached to all molecules in Asn-Leu-Thr occurs only in the RNases from giraffe and moose (normal bold letters). In seven of the other eight sequences Asn-34 is replaced by another residue, resulting in no glycosylation at this site. In six of these, position 35 is occupied by Met, the ancestral residue at this position. It is important to note that in nonruminant mammalian RNases 1 the ancestral sequence Met-Thr (35-36) is conserved (Beintema and Lenstra 1982).

We related these findings to a classification of true ruminants based on feeding ecology and stomach structure in which giraffe and moose are grouped together as large "concentrate selectors" with a diet containing relatively little cellulose fiber and with a relatively simple (primitive) stomach (Hofmann et al. 1976). These are exactly the species investigated by us with much carbohydrate attached to the Asn-Leu-Thr sequence.

The impression of these sequence and glycosylation data is that there is selection against carbohydrate attachment in ruminant ribonucleases, either by replacement of

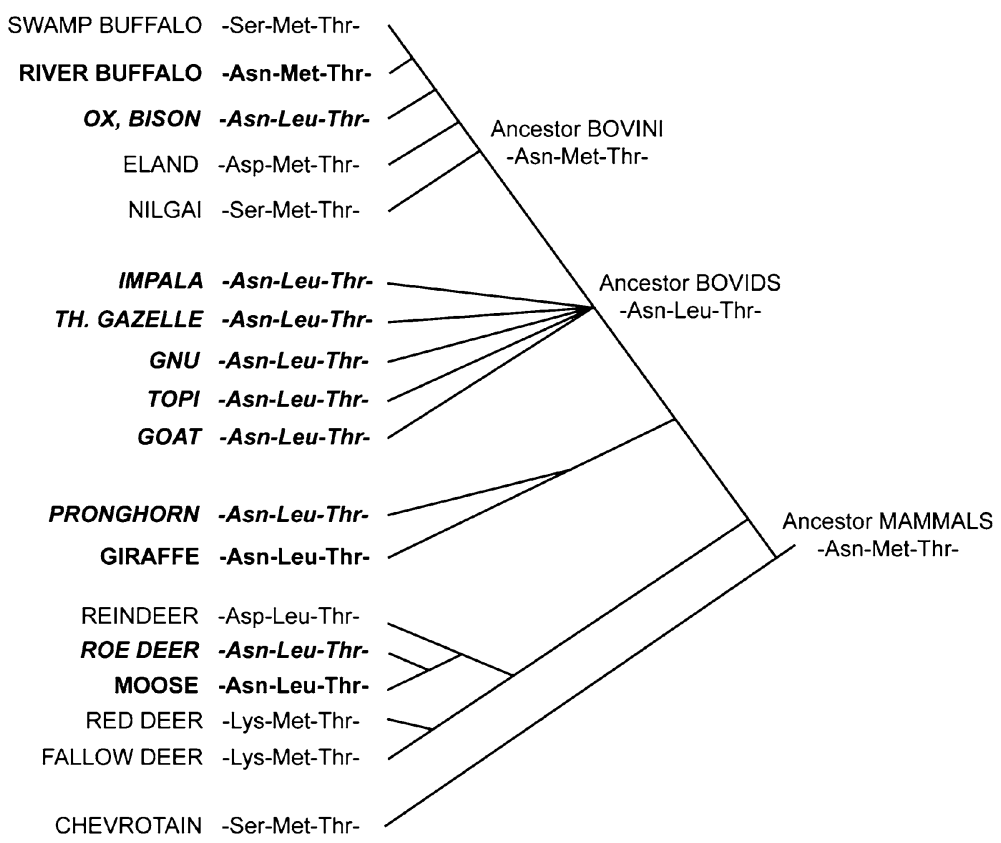

Fig. 1 Amino acid sequences of the carbohydrate attachment site 34-36 in RNases 1 from true ruminants and in several ancestors. Completely glycosylated sequences are in bold letters; partly glycosylated sequences are in bold italic letters. This figure was published in Beintema and Lenstra (1982) and also shows the topology of part of the RNase tree presented in this publication, which did not yet include the RNase sequence of the primitive ruminant chevrotain (Tragulus javanicus) with the nonglycosylated sequence Ser-Met-Thr (Breukelman et al. 2001) 
Asn-34 or replacement of Met by Leu at position 35. The only exception among the ruminants is RNase from Italian river-type water buffalo with a fully glycosylated Asn-Met-Thr sequence (Fig. 1, normal bold letters), while the enzyme from Indonesian swamp-type water buffalo has a nonglycosylated sequence Ser-Met-Thr at positions 34-36 (Sidik et al. 1979).

\section{Results}

As Asn-linked glycosylation in the endoplasmic reticulum mainly occurs on the nascent polypeptide chain, only the primary structure of a carbohydrate attachment
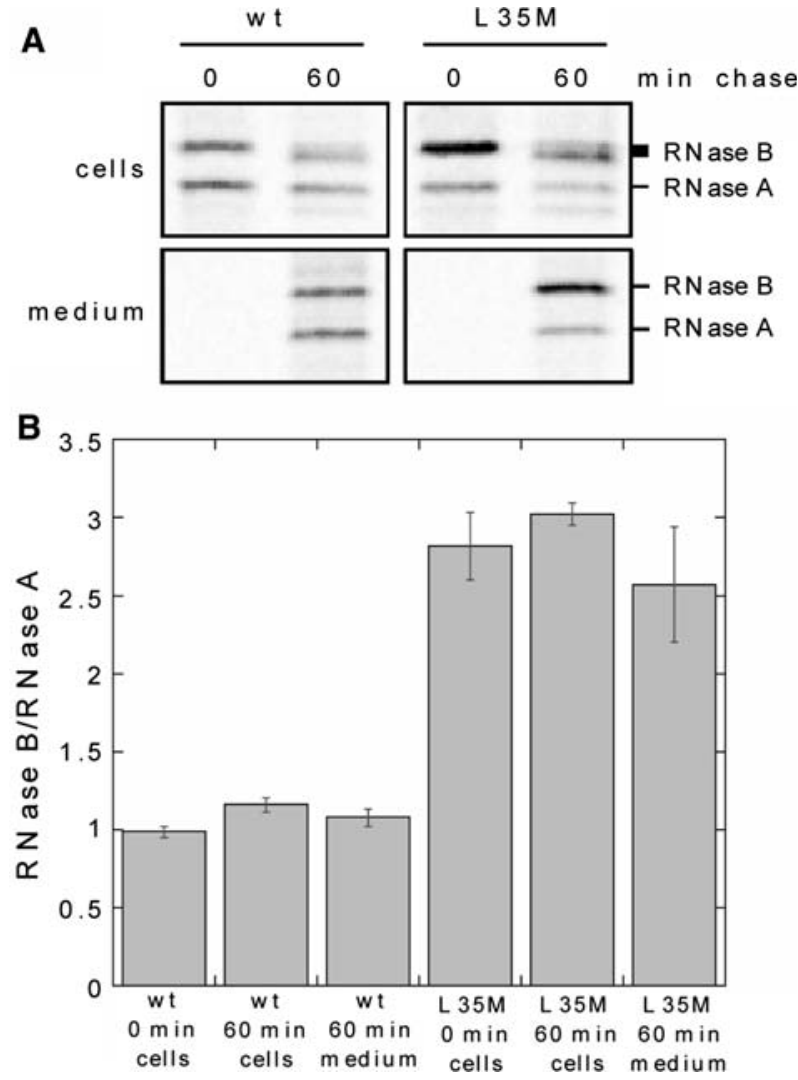

Fig. 2 (a) One representative example of three independent pulse/chase experiments. Pulse ( $3 \mathrm{~min} /$ $\left.0.25 \mathrm{mCi} / \mathrm{ml}^{35} \mathrm{~S} \mathrm{met} / \mathrm{cys}\right)$, direct lysis $(0 \mathrm{~min})$, or chase $(60 \mathrm{~min})$ of wild type $(\mathrm{wt})$ and L35M bovine RNase in Chinese hamster ovary cells. After immunoprecipitation of RNase molecules with RNase antibodies from the lysate (cells) and medium, samples were subjected to reducing SDS-PAGE followed by autoradiography. Note: The cell-associated RNase B at $60 \mathrm{~min}$ is composed of Golgi forms (slowmigrating) and endoplasmic reticulum forms (fast-migrating) (bold bar). (b) After quantification of all three pulse chases using ImageQuant, the mean values of ratio of RNase B to RNase A were plotted using Kaleidograph. Standard deviations are given by the error bars 
site will be of influence on the extent of its glycosylation. Therefore, we predicted that a replacement of the Leu in the Asn-Leu-Thr sequence in bovine RNase 1 to a Met (L35M) will enhance glycosylation (Beintema and Lenstra 1982). When we made this prediction 25 years ago, it was not yet possible to test this experimentally. However, now it is possible to construct a mutant with this replacement and express it in parallel to the wild type in Chinese hamster ovary $(\mathrm{CHO})$ cells and to study the amount of carbohydrate attached in the product obtained (Deprez et al. 2005). As shown in Fig. 2, the ratio of glycosylated (RNase B) to unglycosylated (RNase A) of wild type bovine RNase in CHO cells is about 1, while in vivo in bovine pancreas this ratio is less than 0.2 (Hirs et al. 1953), indicating a clear cell type difference. In the $\mathrm{L} 35 \mathrm{M}$ mutant in $\mathrm{CHO}$ cells there is indeed a three-fold relative increase in glycosylation. The L35M mutant behaves like wild type in $\mathrm{CHO}$ cells, as shown by the stable ratio of glycosylated to unglycosylated forms over $60 \mathrm{~min}$ and by the amounts of secreted (medium) versus cell-associated (cells) forms after $60 \mathrm{~min}$ (Fig. 2). This indicates that the L35M mutant is unchanged in respect to folding and stability, but with enhanced glycosylation.

\section{Discussion}

Barnard (1969) proposed that a high level of pancreatic RNase is an adaptation to digest RNA from the microflora in ruminants and other mammalian species with ruminant-like digestion (fermentation in the stomach). Examples of species with ruminant-like digestion are camels and kangaroo, which have pancreatic RNases with no attached carbohydrate (Beintema and Lenstra 1982). Herbivorous species with fermentation in the cecum, like pig, horse, and rodents, also have a relatively high level of pancreatic RNase. These RNases are completely glycosylated if the consensus sequence Asn-Met-Thr (34-36) is present, and in pig and horse there is also extensive glycosylation at other sites in the molecule (Beintema et al. 1976).

At this moment there is no explanation for why there should be selection against glycosylation of RNases in species with fermentation in the stomach, for which we present evidence in this article. Until now, functional studies on the role of pancreatic RNases in the digestive system of herbivorous mammals and the influence of glycosylation are still waiting for further investigations.

Acknowledgments We thank Prof. Ari Helenius and Friederike Thor for their support.

Open Access This article is distributed under the terms of the Creative Commons Attribution Noncommercial License which permits any noncommercial use, distribution, and reproduction in any medium, provided the original author(s) and source are credited.

\section{References}

Barnard EA (1969) Biological function of pancreatic ribonuclease. Nature 221:340-344

Beintema JJ, Lenstra JA (1982) Evolution of mammalian pancreatic ribonucleases. In: Goodman M (ed) Macromolecular sequences in systematic and evolutionary biology. Plenum Publishing Cooperation, New York, pp 43-73 
Beintema JJ, Gaastra W, Scheffer AJ, Welling GW (1976) Carbohydrate in pancreatic ribonucleases. Eur J Biochem 63:441-448

Breukelman HJ, Jekel PA, Dubois J-Y, Mulder PPMFA, Warmels HW, Beintema JJ (2001) Secretory ribonucleases in the primitive ruminant chevrotain (Tragulus javanicus). Eur J Biochem 268:38903897

Deprez P, Gautschi M, Helenius A (2005) More than one glycan is needed for ER glucosidase II to allow entry of glycoproteins into the calnexin/calreticulin cycle. Moll Cell 19:183-195

Hirs CHW, Moore S, Stein WH (1953) A chromatographic investigation of pancreatic ribonuclease. J Biol Chem 200:493-506

Hofmann RR, Geiger G, König R (1976) Vergleichend-anatomische Untersuchungen an der Vormagenschleimhaut von Rehwild und Rotwild. Z Säugetierk 41:167-193

Martin AJP, Porter RR (1951) The chromatographic fractionation of ribonuclease. Biochem J 49:215-218

Plummer TH, Hirs CHW (1963) The isolation of ribonuclease B, a glycoprotein from bovine pancreatic juice. J Biol Chem 238:1396-1401

Sidik A, Martena B, Beintema JJ (1979) Amino acid sequence differences in pancreatic ribonucleases from water buffalo breeds from Indonesia and Italy. Biochem Genetics 17:1151-1158 